\title{
Extraversion and Neuroticism in Sexually Dysfunctional Men Suffering from Erectile Dysfunction and Premature Ejaculation: A Cross-Sectional Study
}

Marco Silvaggi ${ }^{\star}$, Paolo Maria Michetti, Roberta Rossi, Adele Fabrizi, Costantino Leonardo, Francesca Tripodi, Filippo Maria Nimbi and Chiara Simonelli Department of Psychosexologist, Institute of Clinical Sexology, Rome, Italy

*Correspondence author: Silvaggi Marco, Department of Psychology, Institute of Clinical Sexology, Rome, Italy, Tel: +39 3294193242; E-mail: m.silvaggi@gmail.com

Received date: March 23, 2017; Accepted date: May 02, 2017; Published date: May 06, 2017

Copyright: (c) 2017 Silvaggi M, et al. This is an open-access article distributed under the terms of the Creative Commons Attribution License, which permits unrestricted use, distribution, and reproduction in any medium, provided the original author and source are credited.

\begin{abstract}
The role of personality traits in sexual complaints and dysfunctions is ever more evident. However, the literature is very scarce as to the possible relationships between such personality traits and specific sexual dysfunctions like ED, $P E$ or both, their subtypes as to time of onset and severity levels. The main aim of the present study was to investigate if Neuroticism and Extraversion have different roles and trends in men suffering from PE and/or ED, both lifelong and acquired. Moreover, we verified if, by adopting DSM-IV-TR and DSM-5 criteria for diagnosing PE, some differences emerged in percentages of diagnosed cases. The sample consisted of 222 patients aged 18-70. The International Index of Erectile Function (IIEF-15) was used to assess erectile function, and the Premature Ejaculation Severity Index (PESI) was used to assess the severity of PE dysfunction. Neuroticism and Extraversion were measured with the Eysenck Personality Questionnaire-Revised (EPQ-R). In our results, Neuroticism and Extraversion were dependent on the kind of sexual dysfunction and its severity. These results suggest that type, time of onset and severity of sexual dysfunctions should be considered as related to specific personality characteristics and vice versa.
\end{abstract}

Keywords: Personality traits; Erectile dysfunction; Premature ejaculation; Extraversion; Neuroticism

\section{Abbreviation:}

SD: Standard Deviation; ED: Erectile Dysfunction; PE: Premature Ejaculation; IELT: Intravaginal Ejaculation Latency Time; IIEF: International Index of Erectile Function; EPQ-R: Eysenck Personality Questionnaire-Revised; PESI: Premature Ejaculation Severity Index.

\section{Introduction}

Personality traits are commonly described as global predispositions, consistent across time and responsible for guiding human behavior $[1,2]$. As early as 1971 Eysenck demonstrated that men experiencing sexual difficulties presented higher levels of Neuroticism when compared to sexually healthy men [3]. Unfortunately, the author did not carry out further research on Neuroticism in sexually dysfunctional men. More recently, however, some personality traits have been conceptualized as vulnerability factors in the development of several mental health disorders [4]. Empirical studies have been conducted on the role of personality traits in sexual disorders $[5,6]$, sexual functioning $[7,8]$, sexual behavior [9-11], sexual attitudes [12], and sexual cognitions [13]. Despite their methodological differences, studies conducted with heterosexual male samples have indicated that sexually dysfunctional men scored higher on Neuroticism, compared to sexually healthy men $[5,6]$.

More specifically, Neuroticism has been related to sexual performance anxiety and erectile dysfunction [14-16]. Additionally, Extraversion has been positively associated with male sexual functioning [6,17]. Fagan and colleagues (1991) demonstrated an association between elevated Neuroticism and sexual dysfunctions in men, while Costa and colleagues (1992) confirmed that elevated
Neuroticism was also associated to lowered sexual satisfaction, and Extraversion was associated to higher levels of sexual desire and sexual experiences in men and women $[5,18]$. These findings show the existence of distinctive personality traits related to male Sexual dysfunctions.

Elevated Neuroticism, for example, has been consistently associated to individuals experiencing sexual difficulties, and to major risk factors for the development and maintenance of male sexual problems. Furthermore, Neuroticism has been associated to higher levels of sexual dissatisfaction and marital discomfort [19,20]. Another psychological construct which has been investigated in relation to sexual dysfunctions is alexithymia.

The term alexithymia means "no words for feelings". It was coined by Nemiah and Sifneos in the early 70 s to describe a cluster of personality features recognized among patients with classic psychosomatic disorders [21,22]. It refers to affective deficits in differentiating, identifying, and communicating one's feelings. Alexithymic individuals are also characterized by concrete, utilitarian, and externally focused thoughts rather than introspection, fantasy, and daydreaming. Taylor et al. (1997) proposed that alexithymia reflects a deficit in the cognitive processing of emotions or, more generally, a disturbance in the regulation of emotions [23].

Studies performed by Michetti et al., showed that alexithymia levels were significantly higher in patients with lifelong PE (2007) and ED (2006) $[24,25]$. The authors suggested that a high alexithymia level could contribute not only to the onset and persistence of a sexual disorder, but also to its severity [25]. Higher scores on the alexithymia scale were also associated with a higher probability that individuals would report some tendency to feel worried and troubled about sex because of disturbing thoughts, emotions, and actions arising from their sex lives [26]. Moreover, Rosenheim and Neumann (1991) demonstrated that men experiencing sexual difficulties presented more 
Citation: $\quad$ Silvaggi M, Maria Michetti P, Rossi R , Fabrizi A,Leonardo C, et al. (2017) Extraversion and Neuroticism in Sexually Dysfunctional Men Suffering from Erectile Dysfunction and Premature Ejaculation: A Cross-Sectional Study. Andrology (Los Angel) 6: 1000181. doi: $10.4172 / 2167-0250.1000181$

Page 2 of 8

severe interpersonal anxiety, criticism, guilt, sensitivity to rejection, and external locus of control, when compared to sexually healthy men [14]. Furthermore, a growing body of data has consistently demonstrated that individuals with ED and PE display significantly higher levels of mood disorders such as anxiety and depressive symptoms, lower tolerance to frustration, but also characteristics which are typical of personality disorders, like higher self-expectations, higher emotional control, more sensitivity to failure, and perfectionism $[15,27]$. Although the causality of this relationship remains unclear, it is thought to be bidirectional $[28,31]$.

In spite of PE and ED being very different conditions, with different characteristics and etiology, where ED is affected by lifestyle and clearly age-dependent [32] with a steep increase beyond the fifth decade [33-36] in our literature research we found several papers regarding personality traits and sexual dysfunctions in men, but few studies focused on personality traits and specific sexual dysfunctions like ED and PE (both lifelong and acquired), and on links between such personality traits and dysfunction severity.

Thus, the relationships between personality traits and specific sexual dysfunctions such as ED and PE have been little studied in sex research, although we can hypothesize that different personality characteristics can be risk or protective factors for the onset of different sexual difficulties/dysfunctions and that personality characteristics can also be related to severity.

\section{Hypotheses}

The aim of the present study was to explore the relationships between personality dimensions such as Neuroticism and Extraversion and male sexual dysfunctions, to examine if these variables differ in different kinds of sexual dysfunctions and within dysfunctions with respect to different severity levels. In order to understand the diversity of $\mathrm{ED}$ and $\mathrm{PE}$ as to risk factors and individual vulnerability, we considered that, ED occurs mostly in the later phases of one's sex life that it is linked to lifestyle, relationship duration and so on, and thus it is mostly an acquired dysfunction.

Instead, PE occurs most often in the early phases of one's sex life and it is mostly lifelong. For this reason, we hypothesized that males with PE would report higher Neuroticism and lower Extraversion levels and that males suffering from lifelong dysfunctions would have higher Neuroticism and lower Extraversion scores, because of the primary role of personality in lifelong dysfunctions, while, in acquired dysfunctions, life events or mood could be a main factor. Finally, we wanted to verify whether by adopting DSM-IV-TR or DSM-5 criteria for PE diagnosis, some differences would emerge in percentages of diagnosed men, and if so, what distinguishes individuals who were given a PE diagnosis only according to one of the two criteria sets.

\section{Methods}

A total of 222 men participated in the study. They were recruited from public and private outpatient clinics, between January 2012 and December 2013. Public clinic patients were from Polyclinic Umberto I Hospital of Rome and mostly live in central Italy, with a balanced mix between rural and urban areas. Their levels of education were evenly distributed from lower primary school to graduates. Private patients were the clients of the authors of this study who followed the same criteria as those used in Umberto I for diagnosing sexual dysfunctions and a structured way of administering the questionnaires.
These patients also live in central Italy. All individuals were diagnosed with a sexual disorder according to the Diagnostic and Statistical Manual of Mental Disorders (DSM-IV-TR) [34], clinically assessed by a psycho-sexologist and by an andrologist using a semistructured interview for sexual dysfunctions [35] as well as using medical diagnostic tools (Power Doppler, hormonal tests, etc.) to exclude cases with organic disorders (Table 1).

After its release in 2013, we wanted to verify the impact of the DSM-5 [36] on diagnoses of sexual dysfunctions. Specifically, we wondered whether all patients diagnosed with PE using DSM-IV-TR would still be recognized as such when using DSM- 5 and whether or not the number of diagnosed cases would differ. The Intravaginal Ejaculation Latency Time (IELT) parameter was thus added for PE. [2-5] An exclusion criterion was a clear organic etiology or component in sexual difficulty onset or persistence.

Control population was represented by 348 males (mean age 37.12; SD 12.74) recruited from a non clinical population for the Italian standardization of the EPQ-r test, [37]. Socioeconomic status was predominantly middle and so were educational and occupational levels for clinical and control populations; mean ages were also similar. In accord with these data, statistically significant differences with control population were excluded.

\begin{tabular}{|l|l|l|l|}
\hline Sexual Dysfunction & N & E & N \\
\hline ED lifelong & 23 & 0.997 & -0.201 \\
\hline ED acquired & 106 & -0.104 & $1.676^{*}$ \\
\hline ED & 129 & 0.05 & 1.335 \\
\hline PE lifelong & 61 & -0.35 & $3.040^{\star * *}$ \\
\hline PE acquired & 17 & 0.763 & -0.907 \\
\hline PE & 78 & 0.742 & $1.837^{*}$ \\
\hline
\end{tabular}

Table 1: Statistical differences in personality traits average scores, between different kind of sexually dysfunctional groups and control population.

\section{Procedures}

An institutional review board approved the study. Patients were informed about the purpose of the study and provided with information regarding anonymity and confidentiality issues. Instructions were also provided and a consent form was signed. Subjects participated in the study by filling in the questionnaires anonymously.

\section{Measures}

We evaluated sexual function and personality traits through three tests: Eysenck Personality Questionnaire-Revised (EPQ-R) for all the participants, International Index of Erectile Function 15 (IIEF-15) for patients complaining of ED and Premature Ejaculation Severity Index (PESI) for patients reporting PE. In case of double diagnosis, both instruments were used. If patients were in a relationship, they were asked to report their satisfaction degree on a four-point scale: completely satisfied, pretty satisfied, pretty unsatisfied, and completely unsatisfied. The control group was represented by data emerging from 
Citation: Silvaggi M, Maria Michetti P, Rossi R , Fabrizi A,Leonardo C, et al. (2017) Extraversion and Neuroticism in Sexually Dysfunctional Men Suffering from Erectile Dysfunction and Premature Ejaculation: A Cross-Sectional Study. Andrology (Los Angel) 6: 1000181. doi: $10.4172 / 2167-0250.1000181$

Page 3 of 8

non-sexually dysfunctional sample involved in the Italian standardization of the EPQ-R [37].

\section{EPQ-R}

The EPQ-R examines basic personality dimensions according to Eysenck's theory. It contains 100 questions to be answered with a Yes or No. Results are presented in 6 scales. Three of them-Psychoticism (P), Extraversion (E), Neuroticism (N)- concern the main personality traits. Control scale-Lie (L) assesses the tendency to present oneself in a favorable way [38].

\section{IIEF}

The IIEF is a brief self-administered questionnaire, consisting of 15 items assessing different areas of male sexual functioning: erectile function, orgasmic function, sexual desire, intercourse satisfaction, and overall satisfaction. Psychometric studies supported the discriminant validity of the measure, high internal consistency (Cronbach's alpha values of 0.73 and higher), and test-retest reliability ( $r=0.64$ to $r=0.84)$.

Sensitivity and specificity for detecting treatment-related changes were also supported. This measure allows the calculation of specific indexes for each dimension as well as a sexual function total index, with higher scores indicating better sexual functioning (sexual desire: 2-10; erectile function: 1-30; orgasmic function: 0-10; intercourse satisfaction: $0-15$; overall satisfaction: $2-10$; total: $5-75)$ [39,40]. The Italian version of the IIEF also showed good psychometric characteristics [41].

\section{PESI}

PE severity was evaluated using the PESI, a 10-item self-report investigating the overall experience of $\mathrm{PE}$ on a multidimensional perspective: duration of intercourse, perception of ejaculatory control, sexual satisfaction, personal distress, partner's concern, presence of other sexual dysfunctions, and impact of PE on quality of life [42]. Before reporting our findings, we have to consider the different meaning of the scores in IIEF-15 and PESI respectively. In IIEF, a higher score means a better sexual function, whereas in PESI, it indicates a worse sexual function (erectile function $v s$. severity index).

\section{Analytical strategy}

We examined group differences between sexually dysfunctional and non-dysfunctional men, presenting descriptive statistics separately. Then, we calculated independently for Neuroticism and later for Extraversion their correlations with disorder severity in ED total sample (Table 2) and PE total sample (Table 3) using the severity categories (mild, moderate and severe) indicated by the authors of the tests.

\begin{tabular}{|l|l|l|l|}
\hline ED & N & E & N \\
\hline Mild & 33 & 0.04 & $2.03^{* *}$ \\
\hline Moderate & 70 & 0.85 & 0.38 \\
\hline Severe & 26 & -0.89 & $1.75^{*}$ \\
\hline${ }^{*} p<0.05 ;{ }^{* *} p<0.025 ;{ }^{* * *} p<0.0005$ & & \\
\hline
\end{tabular}

Table 2: Correlations between personality traits and severity of sexual dysfunction in subjects with Erectile Dysfunction.
Moreover, we analyzed group differences in Neuroticism and Extraversion between sexually functional and dysfunctional men divided into classes of different degrees of sexual difficulties. In line with the literature [43-45], we created three categories in the ED sample: severe, moderate and mild levels. As to PE sample, in accordance with the diagnostic scale reported in the PESI, we considered 5 different degrees of dysfunction. We used only three different classes because there were neither men with the mildest nor the most severe form of PE.

\begin{tabular}{|l|l|l|l|}
\hline PE & N & E & N \\
\hline Mild & 7 & $1.90^{*}$ & 0,05 \\
\hline Moderate & 34 & 0.44 & 1.31 \\
\hline Severe & 37 & -0.23 & $2.27^{* *}$ \\
\hline${ }^{*} p<0.05 ;{ }^{* *} p<0.025 ;{ }^{* * *} p<0.0005$ & & \\
\hline
\end{tabular}

Table 3: Correlations between personality traits and severity of sexual dysfunction in subjects with Premature Ejaculation.

The categories were: mild $\mathrm{n}=7$ (from 23 to 44 points on the severity scale), moderate $n=34$ (from 45 to 66 points) and severe $n=37$ (from 67 to 88 points). We also verified the correlation between Neuroticism, Extraversion and age and severity of PE as assessed with PESI, in the general sample, as well as in acquired and lifelong types separately. Finally, using the IELT parameter for PE diagnosis according to DSM-5 manual we evaluated differences in diagnosis and sexual characteristics of males undiagnosed with DSM-5 criteria because of their IELT over one minute. Then, we analyzed separately the correlations between Neuroticism, Extraversion and age with the scores reported in IIEF sexual function sub-scales for all ED patients as shown in Table 4, as well as for only acquired ED and for lifelong ED. All analyses were conducted using IBM SPSS Statistics, Version 20. ANOVA analysis was performed to assess Neuroticism and Extraversion mean value differences between dysfunctional men and control population.

\section{Results}

A total of 222 men participated in the study, aged from 18 to 70 . Mean age was $39.95( \pm 11.52)$. The most common reason for consultation was ED $(n=129 ; 62.32 \%$; mean age $41.48 \pm 11.02) ; 23$ patients $(11.11 \%$; mean age $36.32 \pm 10.86)$ had a lifelong dysfunction, while in 106 ones $(51.21 \%$; mean age $42.42 \pm 10.86)$ ED was acquired. Patients complaining of PE were 78 (37.68\%; mean age $37.39 \pm 12.15)$; 61 patients $(29.47 \%$; mean age $38 \pm 12.01)$ showed a lifelong dysfunction and 17 ones (9.07\%; mean age $33.5 \pm 12.75)$ an acquired PE. Finally, 15 subjects (mean age $36.43 \pm 13.66$ ) presented both ED and PE (double diagnosis).

Subjects with double diagnosis were excluded from the sample because of their small number as a single cluster $(n=15)$, and because of the difficulty in identifying if the two sexual dysfunctions were both lifelong or, if not, which of the two had appeared first. Therefore, our final sample was composed of 207 men.

In the subjects with PE, 24 (30.77\%) declared an IELT over one minute, while $54(69.33 \%)$ declared an IELT under one minute. Only in the second group was PE diagnosable using DSM-5 parameters. In the first group, PESI mean score was 54.95 (moderate PE), while mean score of subjects diagnosable with DSM-5 was 71.50 (severe PE). 
Citation: $\quad$ Silvaggi M, Maria Michetti P, Rossi R , Fabrizi A,Leonardo C, et al. (2017) Extraversion and Neuroticism in Sexually Dysfunctional Men Suffering from Erectile Dysfunction and Premature Ejaculation: A Cross-Sectional Study. Andrology (Los Angel) 6: 1000181. doi: $10.4172 / 2167-0250.1000181$

Page 4 of 8

Among men with an intercourse duration over one minute, only 4 $(16.66 \%)$ were given a severe diagnosis, whereas in those with an intercourse duration under one minute, the diagnosis was severe in 59 cases (75.64\%).

Averages and differences in Neuroticism and Extraversion between different groups based on subtype of sexual dysfunction and nondysfunctional population are presented in Table 1 .

\section{Sexual dysfunction and personality traits}

Results on all recruited patients regarding personality traits revealed some interesting aspects related to sexual dysfunctions. Neuroticism was significantly higher $(\mathrm{p}<0.05)$ in subjects with acquired ED (mean score: $11.61 \pm 5.58$ ) and in subjects with PE (mean score $12.05 \pm 5.17$ ).

In patients with acquired ED, Extraversion was positively related to erectile function (Person's correlation 0.26; $\mathrm{p}<0.001$ ). Statistical significance was higher $(\mathrm{p}<0.001)$ in individuals with lifelong PE who had a mean score of 13.33 ( \pm 5.57$)$, compared with control population with a mean score of $10.54( \pm 5.81)$. In males with the rarest forms of sexual dysfunctions such as lifelong ED and acquired PE we found an opposite trend, but it was not statistically significant.

\section{Severity levels}

As shown in Table 2, Neuroticism was higher in patients with severe and mild ED. Extraversion was lower (but without reaching statistical significance) in severe dysfunctions.

In males with $\mathrm{PE}$, with respect to control population, Extraversion was significantly higher in mild dysfunctions (1.90 $\mathrm{p}<0.005)$, it decreased in moderate $(0.44)$ and it was even lower in severe diagnosis $(-0.23)$, where mean score was lower than general population (Table 3$)$. The opposite trend was observed for Neuroticism, which resulted significantly higher in severe diagnosis $(2.27 \mathrm{p}<0.025)$.

In the sample with moderate severity, Neuroticism mean score decreased to a value still higher than that of general population but the difference was not statically significant, whereas the mean score of subjects with mild severity was similar to that of the general population.

\section{Correlations}

The observed correlations between sexual functioning and personality traits were in line with the above-mentioned concepts. In cases of ED, we observed a quite relevant, positive correlation between Extraversion and erectile function $(0.20)$ and a low but negative correlation with Neuroticism (-0.07).

In accordance with Gomes and Nobre [46], we found a significant negative correlation between Neuroticism and overall satisfaction $(-0.28) \mathrm{p}<0.05)$. The opposite correlation between erectile function (total score in IIEF-15) with Extraversion (0.27 and 0.13) and Neuroticism $(-0.12$ and -0.14$)$ were stronger in acquired dysfunctions. In lifelong $\mathrm{ED}$ we found an evident negative correlation between Neuroticism and overall satisfaction $(-0.41)$, a positive relationship with orgasm function (0.47), a negative correlation between Extraversion and satisfaction in sexual intercourse (-0.32) and a positive correlation with sexual desire (0.55) (Table 4).

As shown in Table 5, in men with PE, PESI scores were negatively correlated with Extraversion $(-0.23)$ and positively with Neuroticism
(0.34). In subjects with lifelong disorders, the correlation was stronger for Extraversion (-0.32) and lower for Neuroticism (0.25).

\begin{tabular}{|c|c|c|c|}
\hline ED & AGE & E & $\mathbf{N}$ \\
\hline AGE & & 0.05 & -0.03 \\
\hline Erectile function (IIEF-5) & -0.08 & 0.20 & -0.07 \\
\hline Intercourse satisfaction & 0.05 & -0.06 & -0.08 \\
\hline Orgasmic function & 0.01 & -0.09 & 0.15 \\
\hline Sexual desire & -0.12 & 0.08 & 0 \\
\hline Overall satisfaction & -0.01 & 0.04 & -0.28 \\
\hline Total score (IIEF-15) & -0.05 & 0.09 & -0.09 \\
\hline \multicolumn{4}{|l|}{ Acquired ED } \\
\hline AGE & 1 & -0.18 & -0.05 \\
\hline Erectile function (IIEF-5) & -0.07 & 0.27 & -0.12 \\
\hline Intercourse satisfaction & 0.03 & -0.04 & -0.12 \\
\hline Orgasmic function & -0.03 & -0.06 & 0.07 \\
\hline Sexual desire & -0.17 & 0 & 0.01 \\
\hline Overall satisfaction & 0.03 & 0.04 & -0.1 \\
\hline Total score (IIEF-15) & -0.07 & 0.13 & -0.14 \\
\hline \multicolumn{4}{|l|}{ Lifelong ED } \\
\hline AGE & 1 & 0.05 & -0.1 \\
\hline Erectile function (IIEF-5) & -0.1 & -0.06 & -0.01 \\
\hline Intercourse satisfaction & 0.27 & -0.32 & -0.04 \\
\hline Orgasmic function & 0.08 & -0.11 & 0.47 \\
\hline Sexual desire & 0.03 & 0.55 & -0.01 \\
\hline Overall satisfaction & -0.1 & 0.01 & -0.41 \\
\hline Total score (IIEF-15) & 0.03 & -0.04 & -0.02 \\
\hline \multicolumn{4}{|c|}{${ }^{*} \mathrm{p}<0.05 ;{ }^{* *} \mathrm{p}<0.025 ;{ }^{* * *} \mathrm{p}<0.0005$} \\
\hline
\end{tabular}

Table 4: Correlations between personality traits and IIEF scores in subjects with Erectile Dysfunction.

\begin{tabular}{|l|l|l|l|l|}
\hline & N & AGE & E & N \\
\hline AGE & & 1 & -0.11 & 0.14 \\
\hline PE Lifelong & 61 & 0.07 & -0.32 & 0.25 \\
\hline PE & 78 & 0.11 & -0.23 & 0.34 \\
\hline PE Acquired & 17 & -0.05 & -0.03 & -0.15 \\
\hline${ }^{*} p<0.05 ;{ }^{* *} p<0.025 ;{ }^{* * *} p<0.0005$ & & \\
\hline
\end{tabular}

Table 5: Correlations between personality traits and severity of sexual dysfunction in subjects with Premature Ejaculation. 
Citation: $\quad$ Silvaggi M, Maria Michetti P, Rossi R , Fabrizi A,Leonardo C, et al. (2017) Extraversion and Neuroticism in Sexually Dysfunctional Men Suffering from Erectile Dysfunction and Premature Ejaculation: A Cross-Sectional Study. Andrology (Los Angel) 6: 1000181. doi: $10.4172 / 2167-0250.1000181$

Page 5 of 8

Finally, we found a negative correlation between age and Extraversion $(-0.25 ; \mathrm{p}<0.05)$, as well as between age and relational satisfaction $(-0.31 ; \mathrm{p}<0.05)$ in subjects with $\mathrm{PE}$.

\section{Differences in PE diagnosis using DSM-IV-TR and DSM-5}

We found that 24 (30.78\%) out of 78 subjects diagnosed for PE with DSM-IV-TR parameters were not diagnosed as such using DSM-5 parameters because of their IELT being over one minute. PESI mean score of patients diagnosable with PE using DSM-IV-TR was 54.95 (moderate PE), while PESI mean score of subjects diagnosable with PE using DSM-5 was 70.50 (severe PE).

\section{Discussion}

Some studies, using a variety of measures, have demonstrated some differences in personality traits in men experiencing sexual problems. The first studies date back to the late '70s and used the Eysenck theory parameters to understand the relation of Neuroticism and Extraversion with sexual arousal $[47,48]$ and sexual attitudes and behavior [49]; in more recent years, Gomes and Nobre [46] used the NEO Five-Factors Inventory to assess Neuroticism and Extraversion, and Allen and Desille [50] used the big five trait taxonomy [51,52] where Neuroticism captures susceptibility to emotional instability and Extraversion captures the quantity and intensity of interpersonal interactions.

However, despite of such studies, personality traits have not yet been systematically studied in sex research with respect to different sexual dysfunctions and their subtypes, although sexual dysfunctions such as
ED or PE are very different from one another and also the differences between lifelong and acquired subtypes could be useful in understanding more about onset and maintenance risk and protective factors.

The only studies assessing a specific sexual dysfunction we found in literature, were the study of Allen and Desille [50], which observed the relationship between personality traits and $\mathrm{ED}$, but used a single item to assess erectile difficulties, and the study of Kurpisz et al. [53] which used IIEF-15 to evaluate ED but assessed PE only in terms of frequency. In this study, our hypotheses were confirmed using validated instruments to assess both sexual functioning and personality dimensions.

In line with Gomes et al. [46] who found sexual functioning was strongly and negatively associated to Neuroticism, and positively associated to Extraversion, and with Peixoto et al. [54] who suggested Neuroticism as a vulnerability factor for the development and maintenance of sexual dysfunction, Neuroticism was hypothesized to constitute a predisposing risk factor for the development and maintenance of sexual difficulties and dysfunctions in different ways and for different dysfunctions.

Extraversion was hypothesized to be a protective factor in onset and maintenance of sexual difficulties and dysfunctions, and we predicted that males with PE would report higher Neuroticism and lower Extraversion levels. Moreover, we hypothesized that Neuroticism was positively related to severity in both $\mathrm{ED}$ and $\mathrm{PE}$ and that Extraversion was negatively related to severity in both ED and PE (Tables 6 and 7).

\begin{tabular}{|l|l|l|l|l|l|l|l|l|l|l|}
\hline & Age & E & N & $\begin{array}{l}\text { Acquired } \\
\text { ED }\end{array}$ & $\begin{array}{l}\text { Erectile } \\
\text { Function }\end{array}$ & $\begin{array}{l}\text { Satisfaction } \\
\text { during } \\
\text { Intercourse }\end{array}$ & Orgasm & Desire & $\begin{array}{l}\text { General } \\
\text { being }\end{array}$ \\
\hline Age & & $-0.24^{* *}$ & -0.023 & $0.200^{*}$ & -0.042 & 0.067 & 0.012 & -0.14 & -0.031 \\
\hline Eatisfaction
\end{tabular}

Table 6: Pearson's correlations between characteristics of subjects with Erectile Dysfunction.

In North American and European samples, higher levels of Neuroticism, and lower levels of Extraversion and openness, have been found to relate to poorer sexual functioning $[6,50,54,55]$.
Our findings confirmed such previous data showing sexual function to be negatively correlated to Neuroticism level. Moreover, data pointed to some differences in specific type and sub-types of sexual dysfunctions, which need to be considered. Finally, we found a 
Citation: $\quad$ Silvaggi M, Maria Michetti P, Rossi R , Fabrizi A,Leonardo C, et al. (2017) Extraversion and Neuroticism in Sexually Dysfunctional Men Suffering from Erectile Dysfunction and Premature Ejaculation: A Cross-Sectional Study. Andrology (Los Angel) 6: 1000181. doi: $10.4172 / 2167-0250.1000181$

Page 6 of 8

negative correlation between age and relational satisfaction in subjects with PE (Table 7).

\begin{tabular}{|l|l|l|l|l|l|l|}
\hline & Age & E & N & Acquired PE & PESI & Relational Satisfaction \\
\hline Age & & $-0.249^{*}$ & 0.035 & -0.179 & 0.077 & $-0.305^{*}$ \\
\hline E & & & -0.129 & 0.215 & $-0.279^{*}$ & 0.247 \\
\hline N & & & & -0.22 & 0.174 & 0.014 \\
\hline Acquired PE & & & & & $-0.466^{* *}$ & 0.013 \\
\hline PESI & & & & & & -0.194 \\
\hline Relational Satisfaction & & & & & & \\
\hline${ }^{*}<<0.05 ;{ }^{* *}<<0.01$ & & & & & & \\
\hline
\end{tabular}

Table 7: Pearson's correlations between characteristics of subjects with Premature Ejaculation.

This is in line with previous literature, which underlines that, in long-lasting couples facing $\mathrm{PE}$, a lower relational and sexual satisfaction emerges both in the man and his partner [56-59].

\section{PE correlation with neuroticism and $\mathrm{E}$}

In accordance with our hypothesis, in subjects with PE, Neuroticism was higher than in the general population, and this difference was more evident in the lifelong subtype. Contrary to our hypothesis, in subjects with PE, Extraversion was not lower than in the control population.

\section{$\mathrm{PE}$ and severity of diagnosis}

In accordance with our hypothesis, in PE subjects, Neuroticism was positively related to dysfunction severity. In fact, in severe diagnoses, Neuroticism was statistically significantly higher than in control population, it decreased in moderate severity and even more so in mild cases. In accordance with our hypothesis, in subjects with PE, Extraversion was negatively related to dysfunction severity. In fact, it was statistically significantly higher than in the control population in mild diagnosis, it decreased in moderate and even more so in severe PE. In accordance with our hypothesis, in subjects with PE, Extraversion was negatively related to the severity score of diagnosis, with a correlation of -0.23 in all men with PE and -0.32 in men with lifelong PE. As we hypothesized, in subjects with PE, Neuroticism was positively related to the severity score of dysfunction, with an overall correlation of 0.25 and of 0.34 in lifelong PE.

\section{ED correlation with neuroticism and extraversion}

The finding that higher levels of Neuroticism and lower levels of Extraversion were associated with greater sexual dysfunction is generally consistent with previous research. Studies have found that higher levels of Neuroticism and lower levels of openness relate to poorer sexual functioning in men and women $[6,8,54,55]$. Such results are more consistent with Kurpisz and collaborators and with Allen et al. that suggest a role of high Neuroticism and Low Extraversion in erectile difficulties $[53,50]$. However, it is important to underline that in the study of Allen and Desille erectile difficulties were detected using a single item [50]. Contrary to our hypothesis, in males with ED, Neuroticism was higher and Extraversion was lower than in the control population, but not in a statistically significant way. Only in acquired ED, was Neuroticism statistically higher than in the control population. This could suggest the role of anxiety as a predisposing factor able to generate a sexual dysfunction/difficulty after an occasional failure in sexual activity. In ED, in line with the literature, Neuroticism resulted negatively related to erectile function and overall satisfaction. A high score in Extraversion personality trait was related to better erectile function, while a low Extraversion was linked to worse sexual functioning in both PE and ED.

\section{ED and severity of diagnosis}

In partial accordance with our hypothesis, ED subjects showed higher Neuroticism than general population in both severe and mild dysfunctions; however, Neuroticism did not show a positive or negative linear correlation with severity. Contrary to our hypothesis, in ED subjects, Extraversion did not have a significant negative relationship with severity of diagnosis. In fact, it was lower in severe diagnosis; it increased in mild diagnosis and even more in severe, but without reaching statistical significance with respect to the general population.

\section{ED and sexual function}

In men with ED, Extraversion was positively and significantly related to erectile function $(0.20)$, while Neuroticism was negatively and significantly related to overall satisfaction $(-0.28)$. In the lifelong ED sample, Extraversion was not significantly related to erectile function but it was strongly positively related to sexual desire (0.55), while Neuroticism was strongly negatively related to overall satisfaction (-0.41). In acquired ED sample, Extraversion was positively and significantly related to erectile function (0.27) and IIEF total score (0.13), while Neuroticism was negatively related to IIEF total score $(-0.14)$. A possible explanation for the role of Neuroticism in acquired ED would be that men with high Neuroticism levels who face a negative sexual experience, like a premature ejaculation or a failure in erection, would experience strong negative effects and this could impact on their feeling of competence. This state of anxiety toward their sexuality might lead to a psychogenic sexual difficulty $[60,61]$ which repeats the negative experience, thus reinforcing concerns about sexuality, in a system that feeds on itself and that it is hard to stop. Our results suggest that Neuroticism could be a dispositional vulnerability factor for the development of sexual difficulties. 
Citation: $\quad$ Silvaggi M, Maria Michetti P, Rossi R , Fabrizi A,Leonardo C, et al. (2017) Extraversion and Neuroticism in Sexually Dysfunctional Men Suffering from Erectile Dysfunction and Premature Ejaculation: A Cross-Sectional Study. Andrology (Los Angel) 6: 1000181. doi: $10.4172 / 2167-0250.1000181$

Page 7 of 8

\section{Conclusions}

We hypothesized that in sexually dysfunctional males, a personality dimension such as Neuroticism would be higher, while a personality trait such as Extraversion would be lower. Our results support these assumptions and some clinical implications should be addressed in assessing and treating sexual dysfunctions. Evaluating an individual's dispositional characteristics together with their specific sexual dysfunctions should be considered part of an integrated sexual therapy protocol. As to the differences between DSM-IV-TR and DSM-5 parameters for PE, our data suggest that using DSM-5 parameters to diagnose PE might result in false negatives among non-severe forms of this dysfunction, although men with moderate and mild PE diagnosis and their partners (if any) report high personal and relational distress regarding their condition. In this situation there is a risk of not providing the appropriate treatment to undiagnosed premature ejaculators. Our results suggest that for lifelong PE and acquired ED, some risk and protective personality factors exist. Therefore, personality factors impeding pharmaceutical or cognitive-behavioral management may be the hidden cause of so called drug resistance or treatment dropout. In these cases, an integrated bio-psycho-social approach, including psycho-sexual, medical and pharmacological aspects, is strongly recommended $[25,62,63]$. However, Extraversion as a protective factor seems to be protective in severity and management of sexual dysfunction with possible implications for clinical work.

\section{Limitations}

Finally, we should consider the limitations of the present study. Given the cross-sectional nature of the research design, we cannot address the question of directionality between personality traits and sexual dysfunctions. In fact, the nature of our research study does not allow us to establish causal relationships. Further studies should be carried out in order to address the question of directionality. In this study, we wanted to draw attention to the role of personality dimensions in certain male sexual dysfunctions. Moreover, the use of a sample from the same geographical area, may have introduced participants' bias, which compromises the generalization of our results. Finally we performed Pearson's correlations only between groups with different kinds of sexual dysfunctions because in control population only mean score and SD in Neuroticism and Extraversion were known. Further investigation is needed in order to understand how personality factors work as predisposing and maintaining factors in the onset and persistence of specific Sexual dysfunctions.

\section{Acknowledgement}

Authors declare no conflict of interest.

\section{References}

1. John OP (1990) The "Big Five" factor taxonomy: Dimensions of personality in the natural language and in questionnaires. Handbook of Personality: Theory and Research New York.

2. McCrae R, Costa P (2004) A contemplated revision of the NEO-Five Factor Inventory. Personality and Individual Differences 36: 587-596.

3. Eysenck HJ (1971) Personality and sexual adjustment. BJ Psych 118:593608.

4. Malouff J, Thorsteinsson E, Schutte N (2005) The relationship between the five-factor model of personality and symptoms of clinical disorders: A meta-analysis. J Psych Behv Assm 27: 101-114.
5. Fagan P, Wise T, Schmidt C, Ponticas Y, Marshall R, et al. (1991) A comparison of five-factor personality dimensions in males with sexual dysfunction and males with paraphilia. J Pers Assess 57: 434-448.

6. Quinta-Gomes A, Nobre P (2011) Personality traits and psychopathology on male sexual dysfunction: An empirical study. The J Sex Med 8: 461-469.

7. Fisher T, McNulty J (2008) Neuroticism and marital satisfaction: The mediating role played by the sexual relationship. J Fam Psychol 22: 112-122.

8. Harris JM, Cherkas LF, Kato BS, Heiman JR, Spector TD (2008) Normal variations in personality are associated with coital orgasmic infrequency in heterosexual women: A population-based study. The J Sex Med 5: 1177-1183.

9. Férnandez ML, Castro YR (2003) The Big Five and sexual attitudes in Spanish students. Soci Behv Personal 31: 357-362.

10. Schenk J, Pfrang H (1986) Extraversion, neuroticism, and sexual behavior: Interrelationships in a sample of young men. Archiv Sex Behv 15: 449-455.

11. Turchik J, Garske J, Probst D, Irvin C (2010) Personality, sexuality, and substance use as predictors of sexual risk taking in college students. J Sex Res 47: 411- 419 .

12. Heaven PC, Fitzpatrick J, Craig FL, Kelly P, Sebar G (2000) Five personality factors and sex: Preliminary finding. Personal Indv Diff 28: 1133-1141.

13. Moyano N, Sierra JC (2013) Relationships between personality traits and positive/negative sexual cognitions. International J Clinic Health Psych 13: 189- 196

14. Rosenheim E, Neumann M (1981) Personality characteristics of sexually dysfunctioning males and their wives. J Sex Res 17:124-138.

15. Tondo L, Cantone M, Carta M, Laddomada A, Mosticoni R, et al. (1991) An MMPI evaluation of male sexual dysfunction. J Clin Psychol 47: 391396.

16. Ugokwe-Ossai R, Ezeokana J, Ucheagwu V (2012) The roles of harassment and personality trait types on sexual response among Nigerian university undergraduates. Ife Psychologia 20: 203-213.

17. Schenk J, Pfrang H, Rausche A (1983) Personality traits versus the quality of the marital relationship as the determinant of marital sexuality. Arch Sex Behav 12: 31-42.

18. Costa PT, Fagan PJ, Piedmont RL, Ponticas Y, Wise TN (1992) The fivefactor model of personality and sexual functioning in outpatient men and women. Psychiatr Med 10:199-215.

19. Bradbury TN, Fincham FD (1988) Individual difference variables in close relationships: A contextual model of marriage as an integrative framework. J Pers Soc Psychol 54: 713-721.

20. Gottman JM (1994) What predicts divorce? The relationship between marital processes and marital outcomes. Hillsdale, NJ: Erlbaum.

21. Nemiah JC, Sifneos PE (1970) Affect and fantasy in patients with psychosomatic disorders. Modern trends in psychosomatic medicine. London: Butterworths 3: 26-43.

22. Nemiah JC, Freyberger H, Sifneos PE (1976) Alexithymia: A view of the psychosomatic process. Modern trends in psychosomatic medicine. London: Butterworths 3: 430-439.

23. Taylor GJ, Bagby RM, Parker JD (1997) Disorders of affect regulation: Alexithymia in medical and psychiatric illness, Cambridge University Press, Cambridge.

24. Michetti PM, Rossi R, Bonanno D, De Dominicis C, Iori F (2007) Dysregulation of Emotions and Premature Ejaculation (PE): Alexithymia in 100 Outpatients. J Sex Med 4:1462-1467.

25. Michetti PM, Rossi R, Bonanno D, Tiesi A, Simonelli C (2006) Male sexuality and regulation of emotions: a study on the association between alexithymia and erectile dysfunction (ED). Int J Impot Res 18: 170-174.

26. Scimeca G, Bruno A, Pandolfo G, Micò U, Romeo VM, et al. (2013) Alexithymia, Negative Emotions, and Sexual Behavior in Heterosexual University Students from Italy. Arch Sex Behav 42: 117-127. 
Citation: $\quad$ Silvaggi M, Maria Michetti P, Rossi R , Fabrizi A,Leonardo C, et al. (2017) Extraversion and Neuroticism in Sexually Dysfunctional Men Suffering from Erectile Dysfunction and Premature Ejaculation: A Cross-Sectional Study. Andrology (Los Angel) 6: 1000181. doi: $10.4172 / 2167-0250.1000181$

Page 8 of 8

27. Safir M, Almagor M (1991) Psychopathology associated with sexual dysfunction. J Clin Psychol 47:17-27.

28. Seidman S, Roose S (2000) The relationship between depression and erectile dysfunction. Curr Psychiatry Rep 2: 201-205.

29. Corona G, Mannucci E, Petrone L, Ricca V, Balercia G, et al. (2006) Psycho-biological correlates of free-floating anxiety symptoms in male patients with sexual dysfunctions. J Andr 27: 86-93.

30. Hartmann U (2007) Depression and sexual dysfunction. J Men's Health Gender 4:18-25.

31. Heiman J (2002) Sexual dysfunction: Overview of prevalence, etiological factors, and treatments. J Sex Res 30: 73-78.

32. Nicolosi A, Laumann EO, Glasser DB, Moreira ED, Paik A, et al. (2004). Sexual behavior and sexual dysfunctions after age 40: The global study of sexual attitudes and behaviors. Urology 64: 991-997.

33. Porst H, Burnett A, Brock G, Ghanem H, Giuliano F, et al. (2013) SOP conservative (medical and mechanical) treatment of erectile dysfunction. J Sex Med 10: 130-171.

34. American Psychiatric Association. (2000). Diagnostic and statistical manual of mental disorders. (4th. edn.) Text Review. Washington, DC.

35. Sbrocco T, Weisberg RB, Barlow DH (1992) Sexual dysfunction interview (SDI). Boston, MA: Boston University: Center for Anxiety and Related Disorders.

36. American Psychiatric Association (2013) Diagnostic and statistical manual of mental disorders (5th edn.) Arlington, VA.

37. Dazzi C (2011) The Eysenck personality questionnaire - Revised (EPQ$\mathrm{R})$ : A confirmation of the factorial structure in the Italian context. Personality and Individual Differences 50: 790-794.

38. Eysenck HJ, Eysenck SBG (1991) Manual of the Eysenck personality scale (adults). London: Hodder and Stoughton 7: 286-294.

39. Rosen RC, Riley A, Wagner G, Osterloh IH, Kirkpatrick J, et al. (1997) The International Index of Erectile Function (IIEF): A multidimensional scale for assessment of erectile dysfunction. Urology 49: 822-830

40. Rosen RC, Cappelleri JC, Gendrano N (2002) The International Index of Erectile Function (IIEF): A state-of-the-science review. Int J Impot Res 14: $226-244$.

41. Cappelleri JC, Rosen RC, Smith MD, Mishra A, Osterloh $\mathrm{IH}$ (1999)Diagnostic evaluation of the erectile function domain of the International Index of Erectile Function. Urology 54: 346-351.

42. Metz ME, McCarthy BW (2003) Coping with premature ejaculation. New Harbinger Publications, Oakland.

43. Mulhall JP, Goldstein I, Bushmakin AG, Cappelleri JC, Hvidsten K (2007) Validation of the erection hardness score. J Sex Med 4:1626-1634.

44. Goldstein I, Lue TF, Padma-Nathan H, Rosen RC, Steers WD, et al. (1998) Oral sildenafil in the treatment of erectile dysfunction. Sildenafil Study Group. NEJM 338:1397-1404.

45. Mulhall J, Althof SE, Brock GB, Goldstein I, Jünemann KP (2007) Erectile dysfunction: monitoring response to treatment in clinical practice recommendations of an international study panel. J Sex Med 4: 448-464.
46. Gomes A, Nobre P (2011) Personality Traits and Psychopathology on Male Sexual Dysfunction: An Empirical Study. J Sex Med 8: 461-469.

47. Kantorowitz DA (1978) Personality and conditioning of tumescence and detumescence. Behav Res Ther 16: 117-123.

48. Farkas GM, Sine LF, Evans IM(1979) The effects of distraction, performance demand, stimulus explicitness, and personality on objective and subjective measures of male sexual arousal. Behav Res Ther 17: 25-32.

49. Bentler PM, Peeler WH (1979) Models of female orgasm. Archives of sexual Behavior 8: 405-423.

50. Allen MS, Desille AE (2017) Personality and sexuality in older adults, Psychology \& Health 32: 843-859.

51. John OP, Naumann LP, Soto CJ (2008) Paradigm shift to the integrative big five trait taxonomy: History, measurement, and conceptual issues. Handbook of personality: Theory and research, New York, Guilford.

52. McCrae RR, Costa PT (2008) The five-factor theory of personality. Handbook of personality: Theory and research, New York, NY.

53. Kurpisz J, Mak M, Lew-Starowicz M, Nowosielski K, Bieńkowski P, et al. (2016) Personality traits, gender rolesand sexual behaviours of young adult males. Ann Gen Psychiatry 15: 28.

54. Peixoto MM, Nobre $\mathrm{P}(2016)$ Personality traits, sexual problems, and sexual orientation: An empirical study. J Sex Marital Thr 42: 199-213.

55. Crisp C, Vaccaro C, Fellner A, Kleeman S, Pauls R (2015) The influence of personality and coping on female sexual function: A population survey. J Sex Med 12: 109-115.

56. Burri A, Giuliano F, McMahon C, Porst H (2014) Female partner's perception of premature ejaculation and its impact on relationship breakups, relationship quality and sexual satisfaction. J Sex Med 11: 2243-2255.

57. Althof SE (2006) Sexual therapy in the age of pharmacotherapy. Annual Review of Sex Research 17: 116-132.

58. Rowland D, Perelman M, Althof S, Barada J, McCullough A, et al. (2004) Self-reported premature ejaculation and aspects of sexual functioning and satisfaction. J Sex Med 1: 225-232.

59. Rowland DL, Patrick DL, Rothman M, Gagnon DD (2007) The psychological burden of premature ejaculation. J Urol 177: 1065-1070.

60. Rajkumar RP, Kumaran AK (2014) The association of anxiety with the subtypes of premature ejaculation: A chart review. Primary Care Companion for CNS Disorders 16: 1-4.

61. Telch MJ, Pujols Y (2013) The Erectile Performance Anxiety Index: Scale Development and Psychometric Properties. J Sex Med 10: 3019-3028.

62. Shmidt HM, Munder T, Gerger H, Frühauf S, Jürgen B (2014) Combination of Psychological Intervention and Phosphodiesterase-5 Inhibitors for Erectile Dysfunction: A Narrative Review and MetaAnalysis. J Sex Med 11: 1376-1391.

63. Althof SE (2006) Prevalence, characteristics and implications of premature ejaculation/rapid ejaculation. J Urol 175: 842-848. 